\title{
EFEITOS DE POTENCIAIS HÍDRICOS DO SUBSTRATO E TEORES DE ÁGUA DAS SEMENTES NA GERMINAÇÃO DE FEIJÃO ${ }^{1}$
}

\author{
VICTOR AUGUSTO FORTI², SILVIO MOURE CICERO ${ }^{3}$, TAIS LEITE FERREIRA PINTO ${ }^{4}$
}

\begin{abstract}
RESUMO - Vários são os fatores capazes de afetar a germinação, entre eles, a disponibilidade hídrica e o teor de água nas sementes são importantes. Dessa forma, o presente trabalho teve o objetivo de avaliar o efeito das disponibilidades hídricas do substrato e dos teores de água das sementes na germinação de diferentes cultivares de feijão e verificar a ocorrência de possíveis efeitos de danos por embebição. Os tratamentos foram constituídos de sementes de sete cultivares de feijão: IACTunã, IAC-Ybaté, IAC-Apuã, IAC-Tybatã, IAC-Votuporanga, IAC-Carioca e Carioca com teores de água iniciais na semente de 9,11 e $13 \%$ e submetidos às disponibilidades hídricas do substrato de $-0,04,-0,1,-0,2$ e - $0,4 \mathrm{MPa}$. Feito isso, foi avaliada a porcentagem de germinação. Concluiu-se que à medida que se reduz os potenciais hídricos, ou seja, com o aumento da deficiência hídrica, a germinação é reduzida para qualquer teor de água nas sementes para os sete cultivares. Em relação ao teor inicial de água nas sementes, não foi verificada sua influência na germinação, ou seja, não foram observados danos por embebição nas condições as quais as sementes foram submetidas.
\end{abstract}

Termos para indexação: Phaseolus vulgaris, qualidade fisiológica de sementes.

\section{INFLUENCE OF WATER AVAILABILITY OF THE SUBSTRATUM AND MOISTURE CONTENT OF THE BEAN SEEDS ON THE GERMINATION}

\begin{abstract}
Many environment's factor can affect the germination, among them, the water availability and the seeds moisture content are important. The objective of the present investigation was to verify the influence of water availability of the substratum and moisture content of several cultivars of beans seeds in their germination and to verify the possible effects of imbibition's damage. The treatments were constituted with bean seeds of seven cultivars: IAC-Tunã, IAC-Ybaté, IACApuã, IAC-Tybatã, IAC-Votuporanga, IAC-Carioca and Carioca with moisture content of 9, 11 and $13 \%$ and submitted the water availability of the substratum of $-0,04,-0,1,-0,2$ and $-0,4 \mathrm{MPa}$. The germination's percentage of each cultivar was evaluated for each condition. Therefore, the conclusion was that when the water availability decrease, with the increase of the hydro deficiency, the germination is reduced to any moisture content condition in the seeds for the seven cultivars. As for the seeds moisture content, it was not checked the influence in the germination. The imbibition's damage was not observed in the conditions which the seeds had been submitted.
\end{abstract}

Index terms: Phaseolus vulgaris, seed physiological quality.

${ }^{1}$ Submetido em 07/03/2008. Aceito para publicação em 10/10/2008.

${ }^{2}$ Graduando em Eng. Agronômica, ESALQ/USP; Piracicaba, SP; bolsista do CNPq: e-mail: vaforti@esalq.usp.br.

${ }^{3}$ Professor titular, Departamento de produção vegetal, ESALQ/
USP; Cx. Postal 9; 13418-900, Piracicaba, SP; bolsita do CNPq: smcicero@esalq.usp.br.

${ }^{4}$ Eng. Agrônoma, Curso de Pós-Graduação em Fitotecnia, FEALQ/USP, Piracicaba-SP; bolsista da FAPESP 


\section{INTRODUÇÃO}

A obtenção de sementes de alta qualidade representa a meta prioritária dentro de um processo de produção, pois, de modo geral, a germinação e a emergência de plântulas são reflexos do potencial fisiológico. No entanto, a análise mais detalhada do problema permite a identificação de vários fatores capazes de afetar a germinação, entre eles, certamente, a disponibilidade hídrica e o teor de água nas sementes são importantes (Marcos Filho, 1986).

A germinação, ou seja, a protrusão da raiz primária e o crescimento da plântula requerem energia e material de reserva para a síntese de novos tecidos. Tanto um como o outro, tornam-se disponíveis através dos processos metabólicos catalisados por enzimas nos tecidos das sementes. Portanto, a água é essencial ao metabolismo celular durante a germinação pelo menos por três motivos: para a atividade enzimática, para a solubilização e transporte dos reagentes e como reagente em si, principalmente, na digestão hidrolítica das substâncias de reserva armazenadas na semente (Marcos Filho, 2005). Para que a germinação ocorra, há um teor mínimo de água que a semente deve absorver e este varia com a espécie (Sá, 1987).

Trabalhos com sementes de diversas espécies têm sido conduzidos sob condições de deficiência hídrica, com o objetivo de determinar o vigor nessas condições de estresse. Para tanto, diversas soluções osmóticas têm sido usadas para simular um ambiente com reduzida umidade. Dentre estas, pode-se citar o PEG (polietileno glicol), o Manitol, o $\mathrm{CaCl}_{2}$ (cloreto de cálcio), o $\mathrm{KCl}$ (cloreto de potássio) e o $\mathrm{NaCl}$ (cloreto de sódio). Quantidades específicas, para cada um destes agentes osmóticos, simulam um determinado potencial osmótico (Braga et al., 1999; Souza e Cardoso, 2000). Entretanto, as diferenças químicas existentes entre estas soluções, podem acarretar diferenças nos resultados de germinação e vigor das sementes, mesmo em potenciais hídricos similares (Souza e Cardoso, 2000). O PEG tem sido amplamente empregado, pois é um polímero de alto peso molecular, não iônico, inerte, que não penetra nas paredes celulares e não apresenta sinais de toxicidade (Bewley e Black, 1994).

Além de ser alterado pelo potencial hídrico do meio, o gradiente hídrico pode ser modificado pela alteração do potencial hídrico das sementes através da mudança no teor de água inicial, o que basicamente acontece com o processo de absorção de água, onde o gradiente diminui à medida que as sementes vão se hidratando. Sementes com baixo teor de água embebem mais rapidamente que as com alto teor de água, pois o gradiente hídrico é muito elevado para as sementes secas e diminui exponencialmente quando as sementes são umedecidas. Assim, reduzindo-se o teor de água da semente, diminuiu-se o potencial hídrico dessa e ocorrem mudanças em sua permeabilidade (Vertucci e Leopold, 1983).

Existem casos em que ocorrem diferenças acentuadas entre potenciais hídricos das sementes e do substrato, podendo acarretar problemas para a germinação da semente, devido à entrada muito rápida de água nas sementes, especialmente em sementes menos vigorosas, ocasionando danos por embebição. As sementes mais secas, com teores de água inferiores a 11\%, são mais sensíveis a essas injúrias (Marcos Filho, 2005). A sensibilidade das sementes a esses danos é controlada por três fatores: o teor inicial de água, a temperatura ambiente e a taxa de absorção de água (Pollock, 1969 citado por Marcos Filho, 2005). Enquanto os dois primeiros são controlados pelo ambiente, o terceiro depende das características intrínsecas da semente, mas geralmente as temperaturas baixas e a embebição rápida de sementes secas favorecem as injúrias (Marcos Filho, 2005).

Diante do exposto, o presente trabalho teve o objetivo de avaliar o efeito das disponibilidades hídricas do substrato e dos teores de água das sementes na germinação de diferentes cultivares de feijão e verificar a ocorrência de possíveis efeitos de danos por embebição.

\section{MATERIAL E MÉTODOS}

A pesquisa foi conduzida no Laboratório de Análise de Sementes do Departamento de Produção Vegetal da Escola Superior de Agricultura "Luiz de Queiroz", da Universidade de São Paulo, em Piracicaba, São Paulo.

Foram utilizadas sete cultivares de feijão (Phaseolus vulgaris L.) obtidos junto ao Instituto Agronômico de Campinas: IAC-Tunã, IAC-Ybaté, IAC-Apuã, IAC-Tybatã, IAC-Votuporanga, IAC-Carioca e Carioca.

Antes de iniciar a condução do experimento, as sementes das sete cultivares foram caracterizadas quanto ao teor de água, a germinação e ao vigor por meio dos testes de condutividade elétrica e envelhecimento acelerado.

Teor de água: o método da estufa foi utilizado para tal determinação, a $105^{\circ} \mathrm{C}$, durante 24 horas, utilizandose duas repetições, conforme a metodologia prescrita nas Regras para Análise de Sementes (Brasil, 1992). Os resultados foram expressos em porcentagem na base úmida.

- Germinação: 200 sementes de cada cultivar, tomadas ao acaso, foram divididas em quatro repetições de 50 sementes. Essas foram distribuídas em substrato de papel 
toalha "germitest" umedecidos com água equivalente a 2,5 vezes a sua massa e mantidos em germinador a $25^{\circ} \mathrm{C}$; as avaliações foram efetuadas no quinto e no nono dia após a instalação do teste, de acordo com os critérios estabelecidos pelas Regras para Análises de Sementes (Brasil, 1992). Os resultados de germinação foram expressos em porcentagem de plântulas normais para cada cultivar. - Condutividade elétrica: utilizaram-se quatro repetições de 25 sementes para cada cultivar. Após a pesagem, as sementes foram submersas em $75 \mathrm{~mL}$ de água destilada, no interior de copos plásticos e, a seguir, mantidas por 24 horas em câmara regulada a temperatura de $25^{\circ} \mathrm{C}$ (Vieira e Krzyzanowski, 1999). Ao final desse período, efetuaram-se as leituras de condutividade elétrica, expressando-se os resultados em $\mu$ mhos. $\mathrm{cm}^{-1} \cdot \mathrm{g}^{-1} \mathrm{de}$ sementes para cada cultivar. - Envelhecimento acelerado: foi conduzido com 4 repetições de 50 sementes para cada cultivar. Essas foram colocadas em caixas plásticas tipo "gerbox" sobre uma tela de aço inox, contendo $40 \mathrm{ml}$ de água ao fundo. As caixas foram mantidas tampadas em câmaras de envelhecimento sob $41^{\circ} \mathrm{C}$ durante 48 horas (Marcos Filho, 1999). Passado esse período, as sementes foram colocadas para germinar da mesma maneira descrita para o teste de germinação. A avaliação foi realizada ao quinto dia após a instalação do teste, computando-se a porcentagem de plântulas normais.

\section{Obtenção de sementes com diferentes teores de água}

Para cada um dos cultivares foram obtidas sementes com os teores de água de 9, 11 e $13 \%$ de água, adotandose o seguinte procedimento para o umedecimento artificial: foram empregadas caixas plásticas do tipo "gerbox". Sobre as telas de cada uma das caixas, foram distribuídas cerca de 250 sementes de cada um dos cultivares e dentro de cada caixa foram colocados $40 \mathrm{ml}$ de água. Estas foram tampadas e levadas para câmaras sob temperatura de $25^{\circ} \mathrm{C}$. Durante a permanência das caixas na câmara, foi realizado, periodicamente, o monitoramento da massa úmida das sementes em hidratação, por meio de pesagens, adotandose como referência o teor de água inicial das sementes até serem atingidos os teores de água desejados.

Por outro lado, para a obtenção de sementes com teores de água inferiores aos iniciais, foram adotados procedimentos de secagem. Aproximadamente 250 sementes de cada tratamento foram colocadas em recipientes metálicos e levados em estufa com circulação de ar sob temperatura de $35^{\circ} \mathrm{C}$. Semelhante ao umedecimento foi realizado periodicamente o monitoramente da quantidade de água retirada das sementes por meio de pesagens e posterior comparação com os pesos necessários para atingir os teores de água desejados.

\section{Disponibilidade hídrica do substrato}

Para o umedecimento do papel foram utilizadas soluções aquosas de Polietilenoglicol Synth (PEG 6000). Visando obter os potenciais de $-0,04,-0,1,-0,2$ e $-0,4 \mathrm{MPa}$, foi calculado a quantidade de PEG 6000 necessária a partir da equação proposta por Michel e Kaufmann (1973), ou seja:

$\psi_{\mathrm{OS}}=-\left(1,18 \times 10^{-2}\right) \mathrm{C}-\left(1,18 \times 10^{-4}\right) \mathrm{C}^{2}+\left(2,67 \times 10^{-4}\right)$ $\mathrm{CT}+\left(8,39 \times 10^{-7}\right) \mathrm{C}^{2} \mathrm{~T}$

em que: $\psi$ os $=$ potencial osmótico (bar); $\mathrm{C}=$ concentração (gramas de PEG 6000/Kg de água destilada) e $\mathrm{T}=$ temperatura $\left({ }^{\circ} \mathrm{C}\right)$, a qual foi considerada a de $25^{\circ} \mathrm{C}$.

Dessa forma, para a obtenção de potenciais hídricos de $-0,04,-0,10,-0,20$ e $-0,40 \mathrm{MPa}$, as soluções aquosas foram compostas respectivamente de 35,55, 78,49, 119,54 e 178,34g de PEG por quilograma de água destilada. Para o preparo dessas soluções, inicialmente fez-se a pesagem da quantidade de PEG 6000 necessária. Após, o PEG 6000 foi misturado com água destilada até a sua total dissolução. Feito isso, as sementes apresentando os três teores de água citados anteriormente $(9,11$ e $13 \%)$, foram colocadas para germinar e avaliadas da mesma forma que para o teste de germinação padrão, em papel-toalha "Germitest" umedecidos com as soluções de PEG 6000 em diferentes concentrações, resultando nas quatro disponibilidades hídricas desejadas.

Dessa forma, considerando os teores de água das sementes e a disponibilidade hídrica dos substratos, foram obtidos 12 tratamentos para cada cultivar.

O delineamento experimental foi o inteiramente casualizado em esquema fatorial $3 \times 4$ (três teores de água e quatro potenciais hídricos do substrato) com comparação das médias efetuadas por meio do teste de Tukey e regressão para o estudo dos diferentes níveis de disponibilidades hídricas.

\section{RESULTADOS E DISCUSSÃO}

\section{Caracterização inicial dos lotes}

$\mathrm{Na}$ Tabela 1 são apresentados os resultados de grau de umidade, porcentagem de germinação, condutividade elétrica e envelhecimento acelerado para as amostras de sementes dos sete cultivares antes da aplicação dos tratamentos.

A análise comparativa dos dados relativos à avaliação da qualidade inicial das sementes revelou que o IACVotuporanga apresentava maiores valores de germinação e vigor, oposto ao que ocorreu com o IAC-Tybatã que apresentou o pior potencial fisiológico. 
TABELA 1. Avaliação da qualidade inicial das sementes dos sete cultivares de feijão: teor de água (T.A.), germinação (G), condutividade elétrica (C.E.) e envelhecimento acelerado (E.A.).

\begin{tabular}{ccccl}
\hline Cultivares & T.A. $(\%)$ & G. $(\%)$ & C.E $($ umho/cm/g) & E.A. $(\%)$ \\
\hline IAC-Tunã & 10,2 & $80,5 \mathrm{c} \mathrm{d} *$ & $135,1 \mathrm{c}$ & $41,6 \mathrm{~d} \mathrm{e}$ \\
IAC-Ybaté & 10,2 & $87,5 \mathrm{a} \mathrm{b} \mathrm{c}$ & $106,1 \mathrm{~b}$ & $59,0 \mathrm{c} \mathrm{d}$ \\
IAC-Apuã & 9,8 & $83,0 \mathrm{~b} \mathrm{c}$ & $94,4 \mathrm{a} \mathrm{b}$ & $74,6 \mathrm{a} \mathrm{b} \mathrm{c}$ \\
IAC-Tybatã & 10,4 & $71,5 \mathrm{~d}$ & $160,3 \mathrm{~d}$ & $26,6 \mathrm{e}$ \\
IAC-Votuporanga & 9,8 & $95,5 \mathrm{a}$ & $83,9 \mathrm{a} \mathrm{b}$ & $91,6 \mathrm{a}$ \\
IAC-Carioca & 10,8 & $89,0 \mathrm{a} \mathrm{b} \mathrm{c}$ & $75,5 \mathrm{a}$ & $70,6 \mathrm{~b} \mathrm{c}$ \\
Carioca & 10,4 & $91,5 \mathrm{a} \mathrm{b}$ & $98,0 \mathrm{a} \mathrm{b}$ & $86,6 \mathrm{a} \mathrm{b}$ \\
\hline
\end{tabular}

*Na coluna, médias seguidas da mesma letra não diferem entre si pelo teste de Tukey em $5 \%$ de probabilidade

Disponibilidades hídricas $\mathrm{x}$ teores de água nas sementes

Nas Tabelas 2, 3 e 4 são apresentados os valores de porcentagem de germinação para cada um dos cultivares em cada uma das condições de disponibilidade hídrica do substrato e teor de água nas sementes. As sementes com teores de água de 9, 11 e $13 \%$ de todos os cultivares apresentaram redução crescente na germinação à medida que as disponibilidades hídricas foram sendo reduzidas (Tabelas 2,3 e 4 e Figuras 1,2 e 3).

TABELA 2. Porcentagem de germinação de sementes dos cultivares de feijão, com teor de inicial de água de $9 \%$, sob quatro condições de disponibilidade hídrica.

\begin{tabular}{|c|c|c|c|c|c|}
\hline \multirow{3}{*}{ Cultivares } & \multicolumn{5}{|c|}{ Teor inicial de água nas sementes de $9 \%$} \\
\hline & \multicolumn{5}{|c|}{ Disponibilidades hídricas (MPa) } \\
\hline & Germ. inicial & $-0,04$ & $-0,1$ & $-0,2$ & $-0,4$ \\
\hline IAC-Tunã & $80,5 \mathrm{c} \mathrm{d} \mathrm{A*}$ & $78,0 \mathrm{~b} \mathrm{~A}$ & $42,0 \mathrm{c} \mathrm{B}$ & $33,0 \mathrm{c} \mathrm{d} \mathrm{B}$ & 6,5 c C \\
\hline IAC-Ybaté & 87,5 b c A & 89,5 a $\mathrm{A}$ & 84,5 a $\mathrm{A}$ & 64,0 a B & 26,0 a C \\
\hline IAC-Apuã & $83 \mathrm{bc} \mathrm{A}$ & 80,5 a b A & $47,5 \mathrm{bc} \mathrm{B}$ & $32,5 \mathrm{c} \mathrm{d} B$ & 11,0 c b C \\
\hline IAC-Tybatã & $71,5 \mathrm{~d} A$ & 78,5 a b A & 58,5 b B & $36,5 \mathrm{c}$ d e $\mathrm{C}$ & 20,5 a b D \\
\hline IAC-Votuporanga & 95,5 a $\mathrm{A}$ & 88,5 a b A & 74,0 a B & 46,5 a b c C & $7,5 \mathrm{c} \mathrm{b} \mathrm{D}$ \\
\hline IAC-Carioca & 89 a b c A & 65,0 c B & $45,0 \mathrm{~b} \mathrm{c} \mathrm{C}$ & $21,5 \mathrm{~d} D$ & $5,0 \mathrm{c} \mathrm{E}$ \\
\hline Carioca & $91,5 \mathrm{a} b \mathrm{~A}$ & 84,0 a b A & 79,5 a $\mathrm{A}$ & 56,0 a b B & $10,5 \mathrm{c} \mathrm{b} \mathrm{C}$ \\
\hline
\end{tabular}

*Na coluna, médias seguidas da mesma letra minúscula e, na linha, mesma letra maiúscula, não diferem entre si pelo teste de Tukey em $5 \%$ de probabilidade

TABELA 3. Porcentagem de germinação de sementes dos cultivares de feijão, com teor de inicial de água de $11 \%$, sob quatro condições de disponibilidade hídrica.

\begin{tabular}{cccccc}
\hline \multirow{2}{*}{ Cultivares } & \multicolumn{5}{c}{ Teor inicial de água nas sementes de 11\% } \\
\cline { 2 - 5 } & Germ. inicial & $-0,04$ & $-0,1$ & $-0,2$ & $-0,4$ \\
\hline IAC-Tunã & $80,5 \mathrm{c} \mathrm{d} \mathrm{A} *$ & $77,5 \mathrm{a} \mathrm{b} \mathrm{A}$ & $53,5 \mathrm{c} \mathrm{d} \mathrm{e} \mathrm{B}$ & $34,5 \mathrm{~b} \mathrm{C}$ & $12,5 \mathrm{~b} \mathrm{c} \mathrm{D}$ \\
IAC-Ybaté & $87,5 \mathrm{a} \mathrm{b} \mathrm{c} \mathrm{A}$ & $83,0 \mathrm{a} \mathrm{b} \mathrm{A}$ & $86,5 \mathrm{a} \mathrm{A}$ & $59,7 \mathrm{a} \mathrm{B}$ & $25,5 \mathrm{a} \mathrm{C}$ \\
IAC-Apuã & $83 \mathrm{~b} \mathrm{c} \mathrm{A}$ & $81,5 \mathrm{a} \mathrm{b} \mathrm{A}$ & $65,5 \mathrm{~b} \mathrm{c} \mathrm{d} \mathrm{B}$ & $32,5 \mathrm{~b} \mathrm{C}$ & $16,5 \mathrm{a} \mathrm{b} \mathrm{c} \mathrm{D}$ \\
IAC-Tybatã & $71,5 \mathrm{~d} \mathrm{~A}$ & $70,5 \mathrm{~b} \mathrm{c} \mathrm{A}$ & $46,5 \mathrm{e} \mathrm{B}$ & $34,5 \mathrm{~b} \mathrm{C}$ & $9,0 \mathrm{~b} \mathrm{c} \mathrm{D}$ \\
IAC-Votuporanga & $95,5 \mathrm{a} \mathrm{A}$ & $86,5 \mathrm{a} \mathrm{A}$ & $81,0 \mathrm{a} \mathrm{b} \mathrm{A}$ & $29,0 \mathrm{~b} \mathrm{~B}$ & $18,5 \mathrm{a} \mathrm{b} \mathrm{C}$ \\
IAC-Carioca & $89 \mathrm{a} \mathrm{b} \mathrm{c} \mathrm{A}$ & $60,5 \mathrm{c} \mathrm{B}$ & $49,5 \mathrm{~d} \mathrm{e} \mathrm{B} \mathrm{C}$ & $35,5 \mathrm{~b} \mathrm{C}$ & $4,5 \mathrm{c} \mathrm{D}$ \\
Carioca & $91,5 \mathrm{a} \mathrm{b} \mathrm{A}$ & $86,5 \mathrm{a} \mathrm{A}$ & $70,5 \mathrm{a} \mathrm{b} \mathrm{c} \mathrm{B}$ & $54,0 \mathrm{a} \mathrm{C}$ & $16,5 \mathrm{a} \mathrm{b} \mathrm{c} \mathrm{D}$ \\
\hline
\end{tabular}

*Na coluna, médias seguidas da mesma letra minúscula e, na linha, mesma letra maiúscula, não diferem entre si pelo teste de Tukey a $5 \%$ de probabilidade 
TABELA 4. Porcentagem de germinação de sementes dos cultivares de feijão, com teor de inicial de água de $13 \%$, sob quatro condições de disponibilidade hídrica.

\begin{tabular}{|c|c|c|c|c|c|}
\hline \multirow{3}{*}{ Cultivares } & \multicolumn{5}{|c|}{ Teor inicial de água nas sementes de $13 \%$} \\
\hline & \multicolumn{5}{|c|}{ Disponibilidades hídricas (MPa) } \\
\hline & Germ. inicial & $-0,04$ & $-0,1$ & $-0,2$ & $-0,4$ \\
\hline IAC-Tunã & $80,5 \mathrm{c} \mathrm{d} \mathrm{A*}$ & 83,0 a b A & 49,5 b B & $25,0 \mathrm{c} \mathrm{C}$ & $7,5 \mathrm{bc} D$ \\
\hline IAC-Ybaté & 87,5 a b c A & 90,0 a $\mathrm{A}$ & 85,0 a $\mathrm{A}$ & 77,5 a $\mathrm{A}$ & 22,0 a B \\
\hline IAC-Apuã & $83 \mathrm{bc} \mathrm{A}$ & 84,5 a b A & 58,5 b B & 29,0 b c C & 12,5 a b c D \\
\hline IAC-Tybatã & $71,5 \mathrm{~d} A$ & 69,5 a b A & $62,5 \mathrm{~b} \mathrm{~A}$ & $35,0 \mathrm{bc} \mathrm{B}$ & 17,5 a b C \\
\hline IAC-Votuporanga & 95,5 a $\mathrm{A}$ & 92,5 a $\mathrm{A}$ & 88,0 a $\mathrm{A}$ & $33,5 \mathrm{bc} \mathrm{B}$ & 17,0 a b C \\
\hline IAC-Carioca & 89 a b c A & 54,5 b B & $59,5 \mathrm{~b} \mathrm{~B}$ & $8,0 \mathrm{~d} \mathrm{C}$ & 0,5 c C \\
\hline Carioca & $91,5 \mathrm{ab} A$ & 87,5 a b A & 84,5 a $\mathrm{A}$ & $42,5 \mathrm{~b} \mathrm{~B}$ & 9,5 a b c C \\
\hline
\end{tabular}

*Na coluna, médias seguidas da mesma letra minúscula e, na linha, mesma letra maiúscula, não diferem entre si pelo teste de Tukey em $5 \%$ de probabilidade.

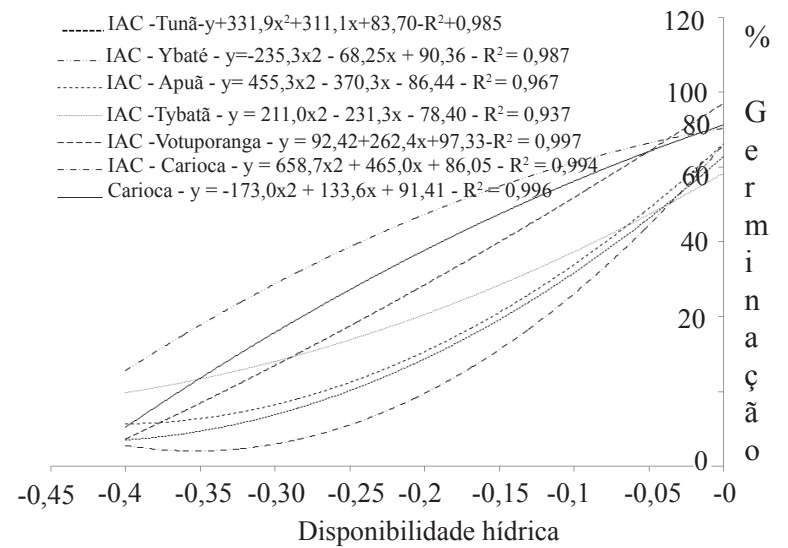

FIGURA 1. Germinação de sementes de feijão, com teor de água de $\mathbf{9 \%}$, submetidas a diferentes disponibilidades hídricas.

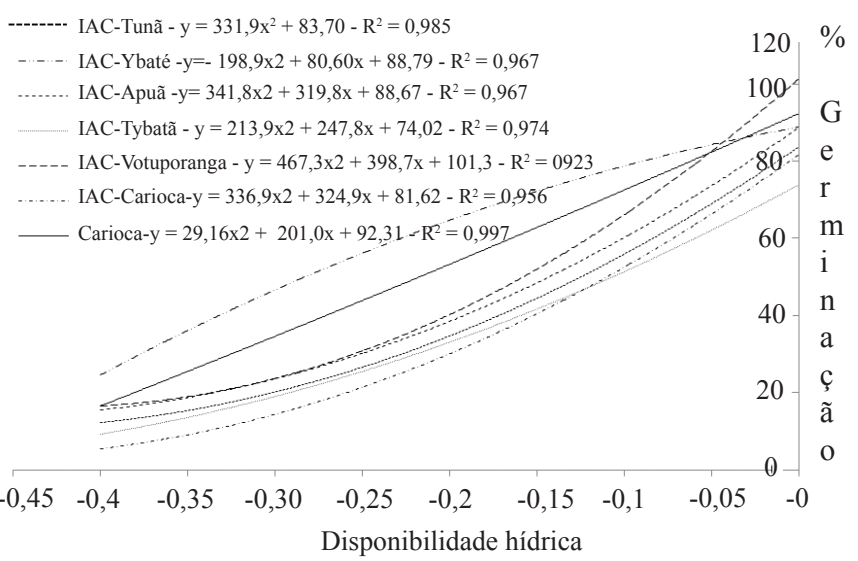

FIGURA 2. Germinação de sementes de feijão com teor de água de $11 \%$, submetidas a diferentes disponibilidades hídricas.

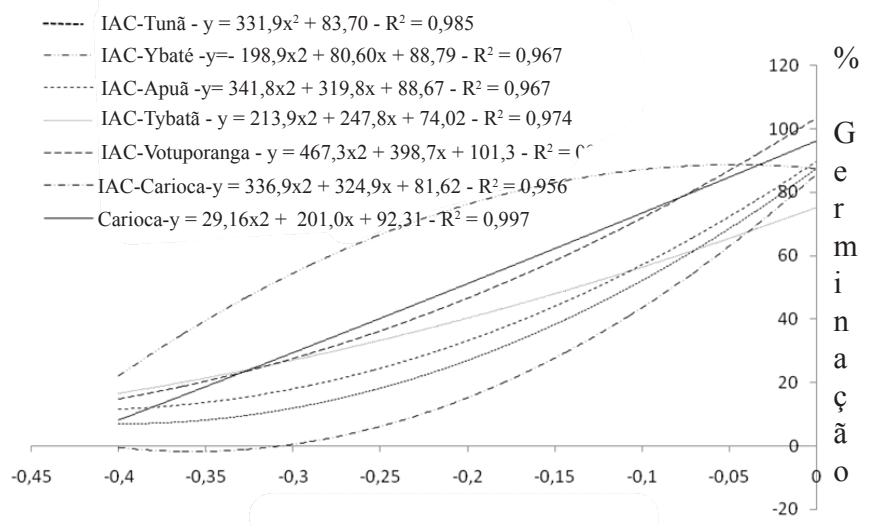

Disponibilidade hídrica

FIGURA 3. Germinação de sementes de feijão com teor de água de $13 \%$, submetidas a diferentes disponibilidades hídricas. 
Resultados semelhantes foram encontrados por Moraes (2003) em sementes de soja e Machado Neto (2006) em sementes de feijão confirmando a diminuição da germinação com a redução do potencial osmótico das soluções no substrato. Para todas as cultivares e teores de água estudados houve drástica redução na germinação quando as sementes foram submetidas a disponibilidade hídrica de - $0,4 \mathrm{MPa}$, sendo que o cultivar IAC-Ybaté apresentou nessa disponibilidade melhor desempenho em comparação as demais cultivares nos três teores de água, apesar de não apresentar o melhor potencial fisiológico inicial (Tabela 1), o que não corrobora com a afirmação feita por Matthews e Powell (1986), na qual espera-se que em sementes menos vigorosas, o processo de embebição seja mais rápido e conseqüentemente a situação de deficiência hídrica seja mais crítica nessas condições, gerando prejuízos mais acentuados para a germinação das sementes.

Pode-se verificar, de maneira geral, que os cultivares estudados respondem de forma distinta as diferentes condições de disponibilidade hídrica. Toledo (2008), afirma que em sementes de soja também ocorre essa resposta diferenciada em relação à embebição entre os cultivares, as quais parecem estar relacionadas às características inerentes a cada um deles.

O cultivar IAC-Carioca, até mesmo em condição de disponibilidade hídrica de $-0,04 \mathrm{MPa}$, apresenta

TABELA 5. Porcentagem de germinação das sementes de cada cultivar, com teores de água de 9, 11 e $13 \%$, sob condição de disponibilidade hídrica de -0,04 MPa .

\begin{tabular}{cccc}
\hline & \multicolumn{3}{c}{ Disponibilidade hídrica de $-0,04 \mathrm{MPa}$} \\
\cline { 2 - 4 } Cultivares & \multicolumn{3}{c}{ Teores iniciais de água nas sementes } \\
& $9 \%$ & $11 \%$ & $13 \%$ \\
\hline IAC-Tunã & $78 \mathrm{~A}$ & $77,5 \mathrm{~A}$ & $83 \mathrm{~A}$ \\
IAC-Ybaté & $89,5 \mathrm{~A}$ & $83 \mathrm{~A}$ & $90 \mathrm{~A}$ \\
IAC-Apuã & $80,5 \mathrm{~A}$ & $81,5 \mathrm{~A}$ & $84,5 \mathrm{~A}$ \\
IAC-Tybatã & $78,5 \mathrm{~A}$ & $70,5 \mathrm{~A}$ & $69,5 \mathrm{~A}$ \\
IAC- & $88,5 \mathrm{~A}$ & $86,5 \mathrm{~A}$ & $92,5 \mathrm{~A}$ \\
Votuporanga & & & \\
IAC-Carioca & $65 \mathrm{~A}$ & $60,5 \mathrm{~A}$ & $72,5 \mathrm{~A}$ \\
Carioca & $84 \mathrm{~A}$ & $86,5 \mathrm{~A}$ & $87,5 \mathrm{~A}$ \\
\hline
\end{tabular}

* Na linha, médias seguidas da mesma letra não diferem entre si pelo teste de Tukey em 5\% de probabilidade grande redução na germinação das sementes em relação a germinação inicial (Tabela 1), não concordando com as considerações feitas por Shioga (1990) que afirmou que a disponibilidade de $-0,04$ pode ser considerada como a de plena disponibilidade, não causando prejuízos a germinação das sementes de feijão.

Segundo Toledo (2008) a avaliação da germinação é uma maneira eficiente de se verificar os efeitos do dano por embebição em sementes de soja. No presente trabalho, não foram observadas diferenças na germinação das sementes com os diferentes teores de água em cada uma das disponibilidades hídricas (Tabelas 5, 6, 7 e 8), nem mesmo na situação extrema de disponibilidade de $-0,4 \mathrm{MPa}$ e teor de água da semente de 9\% (Tabela 8). Mesmo havendo exceções, essas não foram suficientes para afirmar problemas relativos ao dano por embebição.

A Tabela 9 apresenta os dados referentes às diferenças percentuais da germinação em todas as condições, em relação à germinação inicial para os sete cultivares. Diferenças positivas referem-se ao acréscimo na geminação, por outro lado, diferenças negativas referem-se às perdas de germinação. Verificou-se que o IAC-Carioca (6) apresentou grandes perdas percentuais mesmo em condição de $-0,04$ MPa. Porém, em condição de $-0,4 \mathrm{MPa}$, os cultivares que apresentaram melhor desempenho foram os IAC-Ybaté (2) e IAC-Tybatã (4).

TABELA 6. Porcentagem de germinação das sementes de cada cultivar, com teores de água de 9 , 11 e $13 \%$, sob condição de disponibilidade hídrica de -0,1 MPa .

\begin{tabular}{cccc}
\hline \multirow{2}{*}{ Cultivares } & \multicolumn{3}{c}{ Disponibilidade hídrica de $-0,1 \mathrm{MPa}$} \\
\cline { 2 - 4 } & \multicolumn{3}{c}{ Teores iniciais de água nas sementes } \\
& $9 \%$ & $11 \%$ & $13 \%$ \\
\hline IAC-Tunã & $42 \mathrm{~A} *$ & $53,5 \mathrm{~A}$ & $49,5 \mathrm{~A}$ \\
IAC-Ybaté & $84,5 \mathrm{~A}$ & $86,5 \mathrm{~A}$ & $85 \mathrm{~A}$ \\
IAC-Apuã & $47,5 \mathrm{~A}$ & $65,5 \mathrm{~A}$ & $58,5 \mathrm{~A}$ \\
IAC-Tybatã & $58,5 \mathrm{~A}$ & $46,5 \mathrm{~B}$ & $62,5 \mathrm{~A}$ \\
IAC- & $74 \mathrm{~B}$ & $81 \mathrm{~B}$ & $88 \mathrm{~A}$ \\
Votuporanga & & & \\
IAC-Carioca & $45 \mathrm{~A}$ & $49,5 \mathrm{~A}$ & $59,5 \mathrm{~A}$ \\
Carioca & $79,5 \mathrm{~A}$ & $70,5 \mathrm{~A}$ & $84,5 \mathrm{~A}$ \\
\hline * Na linha, médias seguidas da mesma letra não diferem entre si pelo teste \\
de Tukey em 5\% de probabilidade
\end{tabular}


TABELA 7. Porcentagem de germinação das sementes de cada cultivar, com teores de água de 9 , 11 e $13 \%$, sob condição de disponibilidade hídrica de -0,2 MPa .

\begin{tabular}{crrc}
\hline \multirow{2}{*}{ Cultivares } & \multicolumn{3}{c}{ Disponibilidade hídrica de $-0,2 \mathrm{MPa}$} \\
\cline { 2 - 4 } & \multicolumn{3}{c}{ Teores iniciais de água nas sementes } \\
& $9 \%$ & $11 \%$ & $13 \%$ \\
\hline IAC-Tunã & $33 \mathrm{~A} *$ & $34,5 \mathrm{~A}$ & $25 \mathrm{~A}$ \\
IAC-Ybaté & $64 \mathrm{~A} \mathrm{~B}$ & $59,7 \mathrm{~B}$ & $77,5 \mathrm{~A}$ \\
IAC-Apuã & $32,5 \mathrm{~A}$ & $32,5 \mathrm{~A}$ & $29 \mathrm{~A}$ \\
IAC-Tybatã & $36,5 \mathrm{~A}$ & $34,5 \mathrm{~A}$ & $35 \mathrm{~A}$ \\
IAC- & $46,5 \mathrm{~A}$ & $29 \mathrm{~B}$ & $33,5 \mathrm{~B}$ \\
Votuporanga & & & \\
IAC-Carioca & $21,5 \mathrm{~B}$ & $35,5 \mathrm{~A}$ & $14 \mathrm{~B}$ \\
Carioca & $56 \mathrm{~A}$ & $54 \mathrm{~A}$ & $42,5 \mathrm{~A}$ \\
\hline
\end{tabular}

* Na linha, médias seguidas da mesma letra não diferem entre si pelo teste de Tukey em $5 \%$ de probabilidade
TABELA 8. Porcentagem de germinação das sementes de cada cultivar, com teores de água de 9 , 11 e $13 \%$, sob condição de disponibilidade hídrica de -0,4 MPa .

\begin{tabular}{cccc}
\hline \multirow{2}{*}{ Cultivares } & \multicolumn{3}{c}{ Disponibilidade hídrica de $-0,4 \mathrm{MPa}$} \\
\cline { 2 - 4 } & \multicolumn{2}{c}{ Teores iniciais de água nas sementes } \\
& $9 \%$ & $11 \%$ & $13 \%$ \\
\hline IAC-Tunã & $6,5 \mathrm{~A} *$ & $12,5 \mathrm{~A}$ & $7,5 \mathrm{~A}$ \\
IAC-Ybaté & $26 \mathrm{~A}$ & $25,5 \mathrm{~A}$ & $22 \mathrm{~A}$ \\
IAC-Apuã & $11 \mathrm{~A}$ & $16,5 \mathrm{~A}$ & $12,5 \mathrm{~A}$ \\
IAC-Tybatã & $20,5 \mathrm{~A}$ & $9 \mathrm{~A}$ & $17,5 \mathrm{~A}$ \\
IAC- & $7,5 \mathrm{~B}$ & $18,5 \mathrm{~A}$ & $17 \mathrm{~A}$ \\
Votuporanga & & & \\
IAC-Carioca & $5 \mathrm{~A}$ & $4,5 \mathrm{~A}$ & $4,5 \mathrm{~A}$ \\
Carioca & $10,5 \mathrm{~A} \mathrm{~B}$ & $16,5 \mathrm{~A}$ & $9,5 \mathrm{~B}$ \\
\hline
\end{tabular}

* Na linha, médias seguidas da mesma letra não diferem entre si pelo teste de Tukey em $5 \%$ de probabilidade

TABELA 9. Diferenças percentuais em relação à germinação inicial (G.I.) das sementes com diferentes teores iniciais de água de cada um dos cultivares quando submetidos a diferentes condições de disponibilidade hídrica.

\begin{tabular}{|c|c|c|c|c|c|c|c|c|c|c|c|c|c|}
\hline \multirow[b]{3}{*}{ Cultivar } & \multirow[b]{3}{*}{ G.I.* } & \multicolumn{9}{|c|}{ Diferença percentual (\%) } & & & \\
\hline & & \multicolumn{4}{|c|}{$9 \%$} & \multicolumn{4}{|c|}{$11 \%$} & \multicolumn{4}{|c|}{$13 \%$} \\
\hline & & $-0,04$ & $-0,1$ & $-0,2$ & $-0,4$ & $-0,04$ & $-0,1$ & $-0,2$ & $-0,4$ & $-0,04$ & $-0,1$ & $-0,2$ & $-0,4$ \\
\hline $1 * *$ & 80,5 & $-3,1$ & $-47,8$ & $-59,0$ & $-91,9$ & $-3,7$ & $-33,5$ & $-57,1$ & $-84,5$ & 3,1 & $-38,5$ & $-68,9$ & $-90,7$ \\
\hline 2 & 87,5 & 2,3 & $-3,4$ & $-26,9$ & $-70,3$ & $-5,1$ & $-1,1$ & $-31,8$ & $-70,9$ & 2,9 & $-2,9$ & $-11,4$ & $-74,9$ \\
\hline 3 & 83 & $-3,0$ & $-42,8$ & $-60,8$ & $-86,7$ & $-1,8$ & $-21,1$ & $-60,8$ & $-80,1$ & 1,8 & $-29,5$ & $-65,1$ & $-84,9$ \\
\hline 4 & 71,5 & 9,8 & $-18,2$ & $-49,0$ & $-71,3$ & $-1,4$ & $-35,0$ & $-51,7$ & $-87,4$ & $-2,8$ & $-12,6$ & $-51,0$ & $-75,5$ \\
\hline 5 & 95,5 & $-7,3$ & $-22,5$ & $-51,3$ & $-92,1$ & $-9,4$ & $-15,2$ & $-69,6$ & $-80,6$ & $-3,1$ & $-7,9$ & $-64,9$ & $-82,2$ \\
\hline 6 & 89 & $-27,0$ & $-49,4$ & $-75,8$ & $-94,4$ & $-32,0$ & $-44,4$ & $-60,1$ & $-94,9$ & $-38,8$ & $-33,1$ & $-91,0$ & $-99,4$ \\
\hline 7 & 91,5 & $-8,2$ & $-13,1$ & $-38,8$ & $-88,5$ & $-5,5$ & $-23,0$ & $-41,0$ & $-82,0$ & $-4,4$ & $-7,7$ & $-53,6$ & $-89,6$ \\
\hline
\end{tabular}

*Germinação inicial; **1:IAC-Tunã, 2:IAC-Ybaté, 3:IAC-Apuã, 4:IAC-Tybatã, 5:IAC-Votuporanga, 6:IAC-Carioca, 7:Carioca

\section{CONCLUSÕES}

- À medida que se reduz os potenciais hídricos, ou seja, com o aumento da deficiência hídrica, a germinação é reduzida para qualquer condição de teor de água nas sementes para os 7 cultivares.

- Não há influência dos teores de água nas sementes de 9,11 e $13 \%$ no processo de germinação, para todos os cultivares.
- Não há ocorrência de danos por embebição nas sementes de feijão para as condições de disponibilidade hídrica e teor de água estudadas.

\section{REFERÊNCIAS}

BRASIL. Ministério da Agricultura e da Reforma Agrária. Regras para análise de sementes. Brasília, DF: SNDA/ DNDV/CLAV, 1992. 365p. 
BRAGA, L.F.; SOUZA, M.P.; BRAGA, J.F.; SÁ, M.E. Efeito da disponibilidade hídrica do substrato na qualidade fisiológica de sementes feijão. Revista Brasileira de Sementes, DF, v.21, n.2, p.95-102, 1999.

BEWLEY, J.D.; BLACK, M. Seeds: physiology of development and germination. New York: Plenum Press, 1994. 445p.

MACHADO NETO, N.; CUSTÓDIO, C.C.; COSTA, P.R.; DONÁ, F.L. Deficiência hídrica induzida por diferentes agentes osmóticos na germinação e vigor de sementes de feijão. Revista Brasileira de Sementes, v.28, n.1, p. 142148, 2006.

MARCOS FILHO, J. Germinação de sementes. In: SEMANA DE ATUALIZAÇÃO EM PRODUÇÃO DE SEMENTES. Campinas: Fundação Cargill, 1986. p.11-39.

MARCOS FILHO, J. Teste de envelhecimento acelerado. In: KRZYZANOWSKI, F.C.; VIEIRA, R.D.; FRANÇA NETO, J.B. (Ed.) Vigor de sementes: conceitos e testes. Londrina: ABRATES, 1999. cap.3, p.1-24.

MARCOS FILHO, J. Fisiologia de sementes de plantas cultivadas. Piracicaba: FEALQ, 2005. 495p.

MATTHEWS, S.; POWELL, A.A. Environmental and physiological constraints on field performarce of seeds. Hortscience, v. 21, p.1125-1128, 1986.

MICHEL, B.E.; KAUFMANN, M.R. The osmotic potencial of polytylene glycol 6000. Plant Physiology, p.914-916, 1973.

MORAES, G.A.F.; MENEZES, N.L. Desempenho de sementes de soja sob condições diferentes de potencial osmótico. Ciência Rural, v.33, n.2, p.219-226, 2003.

SÁ, M.E. Relações entre qualidade fisiológica, disponibilidade hídrica e desempenho das sementes de soja (Glycine Max (L.) Merrill). 1987. 147f. Tese (Doutoramento em Fitotecnia) - Escola Superior de Agricultura "Luiz de Queiroz", Universidade de São Paulo, Piracicaba.

SHIOGA, P.S. Controle da hidratação e desempenho das sementes de feijão (Phaseolus vulgaris L.). 1990. 106f. Dissertação (Mestrado em Fitotecnia) - Escola Superior de Agricultura "Luiz de Queiroz", Universidade de São Paulo, Piracicaba.

SOUZA, G.M.; CARDOSO, V.J.M. Effects of different environmental stress on seed germination. Seed Science and Technology, v.28, n.3, p.621-630, 2000.

TOLEDO, M.Z. Dano por embebição em sementes de soja em função do teor de água inicial, cultivar e local de produção. 2008. 85f. Dissertação (Mestrado em Agronomia) - Faculdade de Ciencias Agronômicas da UNESP Botucatu, Botucatu.

VERTUCCI, C.W.; LEOPOLD, A.C. Dynamics of imbibition of soybean embryos. Plant Physiology, v.72, p.190-3, 1983.

VIEIRA, R.D. KRZYZANOWSKI, F.C. Teste de condutividade elétrica. In: KRZYZANOWSKI, F.C.; VIEIRA, R.D.; FRANÇA NETO, J.B. (Ed.) Vigor de sementes: conceitos e testes. Londrina: ABRATES, 1999. cap.4, p.1-26. 